\title{
Need Analysis: An Invaluable Step for Successful Autonomous Learning
}

\author{
Sharmin Sultana ${ }^{1}$ \\ ${ }^{1}$ English \& Coordinator, English Language Institute, United International University, Dhaka, Bangladesh \\ Correspondence: Sharmin Sultana, English \& Coordinator, English Language Institute, United International \\ University, Dhaka, Bangladesh. Tel: 88-0171-7534-843. E-mail: sultana@eli.uiu.ac.bd
}

Received: January 27, 2018 Accepted: June 5, 2018 Online Published: June 7, 2018

doi: 10.5539/elt.v11n7p37 URL: http://doi.org/10.5539/elt.v11n7p37

\begin{abstract}
English as a lingua franca now requires the Bangladeshi people to learn this global language with the current demands of the competitive world. What is widely accepted is that a vast majority of Bangladeshi graduates are neither capable to stand out globally as efficient communicators in English nor accomplished enough to meet the challenges of the real world which implies that there are some short comings with the fulfillment of their needs. Hence, the paper investigates the complex world of multi-faced needs of the students at tertiary level, and highlights core consideration for analyzing these needs through a keen eye on the roots of problems. The research combines not only qualitative but also quantitative methods where research paradigm is pragmatic. Finally, the paper shows that need analysis can certainly be invaluable in successful implementation of autonomous learning among students enabling them to take responsibilities of learning in their own hands.
\end{abstract}

Keywords: need analysis, ESL learners, Bangladesh, tertiary level, autonomous learning

\section{Introduction}

In the prevailing myriad scenes of modern world, English language is certainly the language of choice; it has started playing the role of lingua franca. In this regard, a great deal continues to be said about teaching of English at tertiary level in Bangladesh, but the focus has hardly been on fulfillment of the needs of ESL learners. Different philosophers defined need and importance of English language in different ways as well as justified how it is needed for individuals' mental, spiritual, aesthetical and all round development and growth. Hence, it is not unusual that people will be interested in finding out the necessities of the learners in the diverse prevalent approaches, and importance on need analysis is observed in some aspects of curriculum design; nevertheless, close investigation has been remarkably absent.

In Bangladesh, teaching English as a second language is tremendously challenging because nobody can ensure success with any particular formula as proficiency levels of learners and other contexts always vary. Thus the goal of this research is to investigate the needs of ESL learners by exploring which learning styles they desire, which skills should be prioritized, their lacking and suitable methods to enhance their knowledge. The implication of the present study comes in two ways; first of all, the needs of the ESL learners in Bangladesh can be addressed quickly, and secondly, similar vibes of modern trends can be traced here as it encourages autonomous learning which is a modern concept of teaching English as a second language. Finally, it will allow Bangladeshi graduates to become accomplished enough to meet the challenges of the competitive world outside the classroom.

\subsection{Research Hypothesis}

Promoting autonomous learning in an ESL classroom at tertiary level in Bangladesh can be successful if needs of the students are analyzed and addressed effectively.

\subsection{Research Purpose}

To investigate whether and to what extent continuous need analysis can accelerate the acquisition of second language through autonomous learning.

\subsection{Research Questions}

The queries that are of central importance in this paper are given below:

- What are the purposes and reasons of students' learning English? 
- Which strategy/ style/ environment do the students prefer for learning ESL?

- Which particular aspects of English language create difficulties for them?

- If learners' autonomy is promoted, do the learners feel more motivated and responsible towards their own learning?

- If the needs are identified and later on addressed properly, does it enhance successful autonomous learning?

\subsection{Research Scopes}

This study tries to explore the outcomes of need analysis in successful implementation of learners' autonomy in ESL classrooms at tertiary level in Bangladesh. It also aims to open up the scopes to carry out similar investigations on different Bangladeshi students who are struggling to acquire second language within their language classrooms.

\subsection{Research Limitations}

One prominent limitation of this paper is that it is based on some ESL teachers working in one single private university of Bangladesh and some students studying in the same university. Therefore, the results to which the researcher has derived cannot be easily generalized for any set of students in any country.

\section{Literature Review}

\subsection{Need Analysis}

The issue of need analysis and how the ESL learners can get rid of their short comings is an age- old question. The term "analysis of needs" was originated by Dr. Michael Philip West (1888-1973), who was an English language teacher and researcher working extensively in India in the mid-1900s. He asked why learners should learn English and how they should learn English (Ron \& Brown, 1997; Jie, 2013).

Need analysis (also called need assessment) is claimed to be a critical part of the process of curriculum planning in second language learning (Brown, 1995; Richards, 2001). In his book on the curriculum development, Brown (1995, p. 52) states:

“...multiple sources of information should be used in a needs analysis - although the specific combination appropriate for a given situation must be decided on the site by the needs analysists themselves (probably after input from program administration, faculty and perhaps students)."

Munby's Communicative Syllabus Design (1978) is a famous work dealing with needs analysis for English language teaching. Munby presented a series of procedures to identify the expected needs in English. The first is called the "Communicative Needs Processor,' which consist of a series of questions related to the variables in communication, such as the subject matter, the participants, and means of communication. Such variables help pinpoint the specific needs of the learners in the target language. The other is "a profile of needs," which highlights students" needs in the target language; hence, the program designer has only to take these needs into consideration when specifying the elements of the proposed ESP program. 'Need analysis is also fundamental to the planning of General English courses.' (Richards. 1990; Seedhouse, 1995)

\subsection{Learners' Autonomy}

The concept of learners' autonomy obtained consideration of ESL teachers and researchers in 1980s when Henry Holec defined the term as the ability to take charge of one's own learning (Benson, 2006), and much attention was devoted to this concept for creating a better understanding between teachers and students.

In a study Chan (2001) reported that the learners identified the following characteristic qualities of autonomous learners: highly motivated, goal oriented, well organized, hard working, initiative, enthusiastic about learning, flexible, active, willing ask questions, and making use of every opportunities to improve their learning.

Some commonly used definitions of learner autonomy are:

'....a capacity and willingness to act independently and cooperation with others, as a social, responsible person' (Dam, Eriksson, Little, Miliander, \& Trebbi, 1990, p. 102).

'... an attitude towards learning in which the learner is prepared to take, or does take, responsibility for his own learning' ( Dickinson, 1993, pp. 330-341)

'... a capacity for detachment, critical reflection, decision making and independent action' (Little, 1991, p. 4).

Learner autonomy has its own levels which vary with circumstances. The optimal form of learner autonomy is in making complementary contributions which results from students and teachers' negotiation process in planning 
and implementing activities and exercises. Wolter (2000, p. 315) believes that "ownership is an important condition" in which the learners think of classroom and curriculum as their own. Thus, learners become responsible for their own language learning and when their enrolled course finishes "they can continue the learning process more independently and with more self-confidence" (Jordan, 1997, p. 98).

\subsection{Why Need Analysis for successful Autonomous Learning}

If needs are clear, the learning aims can be expressed more easily and the language course can become motivating. If the learners' needs are not taken into account, the course will be based on unstable or irrelevant material, will disillusion the students with the value of instruction or their capacity to learn the language, and will lead to low motivation (Mackay, 1978). To put it simply, the needs assessment provides the researcher with the base on which to build new knowledge by using what the students know to be conveyed (Swale, 1985). If learners have developed their own autonomy, they will then take the necessary responsibility for their own learning and become intrinsically motivated and engage themselves in their learning initiatively and actively (Little, 2006). Researchers suggest that autonomy supportive teaching practices are associated with greater positive outcomes in the classroom. For example, Chirkov and Ryan (2001) studied Russian and US high school students and found that students' perceptions of both teacher and parent autonomy support were associated with greater internalization of academic motivation and a way to facilitate internalization is that teachers provide students with a meaningful rational or why a learning activity is useful. Autonomous learners understand the purpose of their learning programme, explicitly accept responsibility for their learning, share in the setting of learning goals, take initiatives in planning and executing learning activities, and regularly review their learning and evaluate its effectiveness (cf. Holec, 1981; Little, 1991).

\section{Research Methodology}

\subsection{Methods}

This study basically combines both qualitative and quantitative research methods, where research paradigm is pragmatic. While doing so, there is an attempt to triangulate the researcher's observation with primary and secondary data.

\subsection{Subjects}

The 25 respondents were students who were in summer trimester, 2017 (May-August) doing a core course called 'Basic English' as part of their BBA (Bachelor of Business Administration) programme in a leading private university in Bangladesh.

\subsection{Instrument of the Data Collection}

The main instrument of this case study was questionnaires. Moreover, there were other instruments, like, informal interviews, journal writing, focused group discussions (FGDs), etc.

\subsection{Data Analysis}

Questionnaire-1 was given to the students in the first class of the trimester to explore their needs, and after collecting them, they were analyzed; then, the topics and materials to be taught in the classes were designed accordingly. Questionnaire-2 was given to the students in the middle of the trimester to find out whether they were actually getting benefitted by autonomous learning after need assessment, and whether there was any need for further improvement. Questionnaire- 3 was given to the students at the end of the trimester after applying autonomous learning throughout the trimester. Questionnaire- 4 was given to five ESL teachers to learn about their views on students' preferred learning styles, strategies, classroom environment so that their valuable thoughts could also be analyzed for successful autonomous learning through need analysis. Then all collected data from the questionnaires, informal interviews, journals written by students were analyzed qualitatively and quantitatively through some procedures. In this method, the researcher carefully read the answers written by the subjects in the questionnaire, took notes while taking informal interviews or group discussions, monitored the students' performance in different activities, evaluated the students' journals.

\section{Result}

The results gained from different questionnaires are given in the appendix. Nevertheless, to sum up the results, the following aspects are of immense concern:

\subsection{Need Analysis Revealed Some Fundamental Issues}

The results revealed that after need analysis ESL students were well aware about their learning objectives and goals. They identified their preferred learning and teaching strategies, styles and also convenient environment. 
These results are shown in the appendix along with the questionnaires. They further identified their areas of weakness which resulted from some deep root causes that will be elaborated later on in the discussion part. Moreover, due to these short comings, they were facing challenges in general (listening, speaking, reading, writing) and functional (using English in transactional activities, in different social contexts, in creative ways) language skill development.

\subsection{Autonomous Learning Brought Some Positive Outcomes}

With the help of need analysis, it was easier to give more concentration through learners' autonomy on learning materials, tasks, strategies, specific areas of language where students lag behind. After promoting learners' autonomy, students were self-motivated, sincere, persistent and responsible towards their own learning. At the beginning of the trimester, the students were excessively dependent on their reference books, but with the passage of time, they were able to do their work independently taking charge on their own. They could distinguish their achievements and flaws. Since there was progress in attainment, they started reacting firmly to complications in their learning. The students initiated some effective approaches to expand their knowledge.

\section{Discussion}

English language is no longer a necessity only; it has become a language of choice, and an ESL classroom can certainly offer the right platform for skills development so that the graduates are accomplished enough to meet the challenges of the 'competitive', 'real' and 'much bigger' world outside the classroom. To empower the students to achieve all these opportunities and possibilities, we need to find out the challenges the students encounter, and facilitate them to overcome the impediments by promoting autonomous learning.

\subsection{Why Need Analysis Is Needed}

Need analysis is fundamental for successful language learning and also for effective teaching. When we are deciding how to go about needs analysis with a group of students, we need to consider about two questions:

- What do we need to know about them?

- How can we find it out?

The goals and objective of students' learning English can be identified through need analysis; moreover, their preferred learning styles, areas of weaknesses can be discovered too. There are three times the continuous need analysis can be done, such as:

- Stage-1: The planning stage - it can be the first class or even before the class starts if arrangements are possible, mainly to know about students' various needs.

- Stage-2: The teaching stage - it can be done in the middle of the semester to perceive their progress or their preferred strategies or ambiance.

- Stage-3: The re-planning stage - it can be done at the end of the semester so that final results could be gathered and modifications could be included for next set of students for better outcomes.

It is found that tertiary level students are facing diverse hindrances in developing language skills; even a vast majority of the graduates produced by the universities of Bangladesh are not efficient communicators in English which implies that there are some short comings with the fulfillment of the needs of the students. The paper investigates the complex world of multi-faced needs of the students at tertiary level, and highlights core consideration for analyzing these needs through a keen eye on the roots of the problems. Through questionnaires, informal interviews, FGDs, the root problems that were identified are:

\subsubsection{The Language Itself}

The first and foremost problem faced by the students in an ESL classroom at tertiary level is the 'Language' itself. English, not being the native language, elicits some difficulties among Bangladeshi learners when they come across communication that requires expertise in English language though many of them might have bright academic results in their previous exams in schools or colleges. They sometimes face language shock, that is, they experience doubt and possible confusion when using L2 (Schumann, 1978c). As English is not their mother tongue, they remain under constant pressure of accuracy, appropriateness and fluency. From the researcher's nine years' of teaching experience in a university in Bangladesh, she has often found students saying, "Sorry, mam. I can explain in Bangla, but I can't explain in English. I don't find the right word at the right moment." Moreover, there are mistakes in the structures, and sometimes too many pauses are prevalent. They always try to compare the structures of sentences in English with their mother-tongue which confuses them a lot as they are not same. The root cause of such kind of problems was 'lack of enough exposure of all skills of English language in ESL 
classroom in school and college'. In most schools and colleges, listening and speaking are ignored completely; reading is less emphasized; much focus is given on writing and grammar which is also most of the time devoid of communicative approach.

\subsubsection{The Content of the Lesson}

Sometimes learners consider 'the content' as a problem itself. They are learning a foreign language, so naturally different cultures also come into play simultaneously. Guest (2002) has argued that attempts to identify national characteristics for the purpose of comparing and contrasting cultures, leads to oversimplification and stereotypes of cultural characteristics. Moreover, because of differences in activities, norms, rituals, traditions, etc. those are found in the content of the lessons being taught in the English classroom, students from different background sometimes cannot cope up with that successfully; ultimately, frustration, anxiety and stress arise. While practicing listening from New Headway Pre-Intermediate Student's Book in a university in Bangladesh, most of the students feel awkward when they hear Mrs. Snell (T 1.4) talking openly about 'boys and girls living together and not married' as this is entirely against their norms and rituals. In Hollywood Kids [New Headway Pre-Intermediate Student's Book], 13 years old Trent has a credit card with Bangladeshi students' great surprise. Consequently, these experiences may lead to culture shock (Sultana, 2011). Culture shock is the term used to denote the anxiety and stress reactions that some people experience when they live in a cultural and linguistic environment that is significantly different from their own (Schumann, 1978c).

\subsubsection{The Teaching Styles \& Strategies}

It is often found that in ESL classroom in most schools and colleges, teachers take the role of 'Knowledge Provider'. They consider themselves as 'Authority' and teaching-learning process is most of the time teacher-centred without much understanding of students' needs. Thus their demands remain unattended; learning stays incomplete; success becomes impossible.

\subsubsection{The Learning Environment}

A congenial atmosphere can accelerate acquisition of English as a second language. But if we consider practical scenario, we find that most of the classrooms in our schools and colleges are not still well-equipped with modern technology. Some teachers still take tradition roles of strict, reserved, rude teachers which hinders friendly learning environment in the classroom.

\subsubsection{The Assessment Process}

Mainly writing is assessed in schools and colleges, and there is no speaking or listening test at all. But expertise is needed in every sector to become a successful global communicator, so much care needs to be taken in this regard.

\subsection{How the Challenges Can Be Met Through Autonomous Learning}

The obstacles the students encounter are multi-faced. Each has his/ her own weakness, own priority, own strategy; therefore, only autonomous learning can be effective in treating all these difficulties.

\subsubsection{Addressing Individual Needs}

The needs differ from person to person and the ESL classroom needs to address every student's requirements. Once needs are identified, the goals can be set more accurately. The program designer has to take these needs into consideration when specifying the elements of the proposed program; hence, the language course can be fruitful. Generally, "learners do want and appreciate the opportunity to express their views about their course and wish to exercise some degree of control over the way the course proceeds" (Davies, 2006, p. 8).

\subsubsection{Focusing on Communication}

The communication process should be learner centered. All four skills of language should be equally accentuated, valued and assessed. If the facilitator can gather a diverse set of resources, and ensure their maximize exposure,there is higher possibility of improvements in general and functional language skills of the learners.Expressive arts like drama, role play, individual and group presentations can be successfully used for language learning. As the learners have different goals, strategies and proficiency level, they learn in different ways. "The emphasis on pair or group work and problem-solving allows for these differences" (Dudley-Evans \& St John, 2000, p. 27). It seems from the data that students prefer to learn under 'communicative' conditions with a positive classroom atmosphere.

\subsubsection{Taking the Role of Facilitator and Motivator}

From the data, it is obvious that students don't like very strict and rigid teachers. For fruitful autonomous learning 
to take place, the ESL teachers have to constantly motivate the learners, guide them to the right direction, and appreciate their achievements. Instead of over powering own self as an omniscient God they should act only as facilitator and motivator. Gardner and Lambert (1972) define 'motivation' in terms of the L2 learner's overall goal or orientation. The motivated individual is goal-oriented, persistent, attentive and aroused.

\subsubsection{Ensuring Friendly Environment}

All students learn best if friendly environment prevails in the classroom. Teachers must praise at students' slightest progress and give them encouragement. Thus they can become highly encouraged and exhilarated, and then obtain self-confidence in achieving their goals. The trust and cooperation between the teacher and the students makes the students feel comfortable and secure in the classroom. Only then the students can have the confidence to adventure in language learning (Voller, 1997).

\subsubsection{Taking Learning Responsibilities on Students' Own}

According to W F Mackey (1965), "Good teaching is no guarantee of good learning, for it is what the learner does that makes him learn". If learners have developed their own autonomy, they will then take the necessary responsibility for their own learning and become intrinsically motivated and engage themselves in their learning initiatively and actively (Little, 2006). Students will ultimately become independent from teachers and teaching and thus in education, "the development of autonomy and self-sufficiency may be desirable ends" (Dickinson, 1994, p. 3).

\section{Conclusion}

The objective of this study was to establish the prospective of needs analysis and later meeting the challenges through autonomous learning in an ESL classroom at tertiary level in Bangladesh. The study has focused on students' learning goals, preferred strategies, present lacking and alternative methodologies. In this research need analysis has been done in three stages - planning, teaching and re-planning stages, and it is found that students need a slightly varied time length to reach the learning destination successfully due to their different level of language proficiency, and in this regard autonomous learning plays a vital role. Emphasizing topics and themes which are related to students' needs and interest and compatible with their background, experience and abilities motivates them to learn, and encourages them to build self-confidence and positive attitudes towards learning, taking responsibilities on their own. Thus a direct link can be drawn from needs to aims to course design, fruitful classroom implementation and successful outcomes.

\section{Remedial Recommendations}

Based on an analysis of the different responses among learners, it is found that the needs analysis data can suggest a direction for materials design to tackle different problems among ESL learners through successful implementation of autonomous learning. According to the results and findings of the study, it is recommended that in attempts to promote a higher level of learner autonomy in Bangladesh, it requires a different way of thinking about classroom dynamics and the roles of teachers, as well as learners. This study may draw the attention of the scholars, educationalists and course designers to conduct more studies using multiple methods and sources of information about student/ teacher attitudes in order to make the results more valid and more widely applicable.

\section{References}

Benson, P. (2006). Autonomy in language teaching and learning. Language Teaching, 40(1), 21-40. https://doi.org/10.1017/S0261444806003958

Brown, J. D. (1995). The elements of a language curriculum. Boston: Heinle \& Heinle.

Chan, V. (2001). Readiness for learner Autonomy: What do our learners tell us? Teaching in Higher Education, 6(4), 505-519. https://doi.org/10.1080/13562510120078045

Chirkov, V. I., \& Ryan, R. M. (2001). Parent and teacher autonomy-support in Russian and U.S. adolescents: Common effects on well-being and academic motivation. Journal of Cross-Cultural Psychology, 32, 618-35. https://doi.org/10.1177/0022022101032005006

Dam, L., Eriksson, R., Little, D., Miliander, J., \&Trebbi, T. (1990). Towards a definition of autonomy. In T. Trebbi (Ed.), Third Nordic workshop on developing autonomous learning in the FL classroom (pp.102-103).

Davies, A. (2006). What do learners really want from their EFL course? ELT Journal, 60(1), 3-12. https://doi.org/10.1093/elt/cci076

Dickinson, L. (1994). Learner autonomy: What, why and how? In V. J. Leffa (Ed.), Autonomy in language learning (pp. 2-12). Porto Alegre: Universidade/UFRGS. Retrieved November 5, 2008, from 
http://coralx.ufsm.br/desireemroth/publi/autonomy.pdf\#page=15

Dickenson, L. (1993). Talking shop: Aspects of autonomous learning, An interview with Leslie Dickinson. ELT Journal, 47(1), 330-341.

Dudley-Evans, T., \& St John, M. J. (2000). Developments in English for specific purposes: A multidisciplinary approach. Cambridge: CUP.

Dulay, H., \& Burt, M. (1977). Remarks on creativity in language acquisition. In M. Burt, H. Dulay, \& M. Finocchiaro (Eds.). Viewpoints on English as a Second Language. New York: regents.

Gardner, R. C., \& Lambert, W. E. (1972). Attitudes and motivation: Second language learning. Newbury House.

Guest, M. (2002). A critical 'checkbook' for culture teaching and learning. ELT Journal, 56(2), 154-161. https://doi.org/10.1093/elt/56.2.154

Holec, H. (1981). Autonomy and Foreign Language Learning. Oxford: Pergamon. (First published 1979, Strasbourg: Council of Europe.)

Jie, C. (2013). English Learner Needs Analysis: A case Study of Beijing Institute of Petrochemical Technology (BIPT). International Journal of Humanities and Social Science, 3(1), 178-182.

Jordan, R. R. (1997). English for academic purposes: A guide and resource book for teachers. Cambridge: CUP. https://doi.org/10.1017/CBO9780511733062

Little, D. (1991). Learner Autonomy 1: Definitions, Issues and Problems. Dublin: Authentik.

Little, D. (2006). Learner autonomy: Drawing together the threads of self-assessment, goal-setting and reflection. $\quad$ Retrieved 4 March, 2009, from http://www.ecml.at/mtp2/ELP_TT/ELP_TT_CDROM/DM_layout/00_10/06/06\%20Supplementary\%20text .pdf

Mackey, W. F. (1965). Language Teaching Analysis. London: Longman

Mackay \& Mountford, A. J. (1978). English for Specific Purposes. London: Longman.

Munby, J. (1978). Communicative Syllabus Design. Cambridge: Cambridge University Press.

Richards. J. (2001).Curriculum development in language teaching. Cambridge: Cambridge University Press. https://doi.org/10.1017/CBO9780511667220

Schumann, J. (1978c). The Acculturation model for second language acquisition. In R. Gingras (Ed.). Second Language Acquisition and Foreign Language Teaching. Arlington, VA. Center for Applied Linguistics.

Seedhouse, P. (1995). Needs analysis and the General English classroom. ELT Journal, 49(1), 59-65. https://doi.org/10.1093/elt/49.1.59

Sultana, S. (2011). Teaching English in a Cross-cultural Context: Challenges and Directions. Journal of NELTA, 16(1-2), 114-122.

Voller, P. (1997). Does the teacher have a role in autonomous learning? In P. Benson, \& P. Voller (Eds.). Autonomy and Independence in Language Learning (pp. 98-113). London: Longman.

Wolter, B. (2000). A participant-centered approach to INSET course design. ELT Journal, 55(4), 311-318. https://doi.org/10.1093/elt/54.4.311 


\section{Appendix: A}

\section{Appendix A: Survey Questionnaire-1 with results (25 students participated)}

Name:

Current Profession:

Age:

Date:

Please read the following instructions before you fill up the questionnaire:

[The questionnaire given below has been designed to get a general idea about you as per requirement of a small survey. This survey is conducted for a research paper titled "Need Analysis: An Invaluable Step for Successful Autonomous Learning". Therefore, it will be highly appreciated if you provide as much information as you can. Your honesty and patience will be highly respected.]

Purposes and reasons: Why are you learning English?

\begin{tabular}{|c|c|c|}
\hline Reasons & Yes & No \\
\hline To get better grades in English courses & $64 \%$ & $36 \%$ \\
\hline To pass in exam as English course is a basic requirement & $56 \%$ & $44 \%$ \\
\hline To be able to understand books in English in all courses & $88 \%$ & $12 \%$ \\
\hline To be skilled in English as it is an important world language & $100 \%$ & $0 \%$ \\
\hline To get a better job after graduation & $76 \%$ & $24 \%$ \\
\hline
\end{tabular}

Ways of learning: How do you like to learn?

\begin{tabular}{|c|c|c|}
\hline Ways & Yes & No \\
\hline Through learning grammar only & $4 \%$ & $96 \%$ \\
\hline Through communicative approach having focus on all four skills & $92 \%$ & $8 \%$ \\
\hline Taking learning responsibilities on my own & $68 \%$ & $32 \%$ \\
\hline Only by teachers' lectures & $4 \%$ & $96 \%$ \\
\hline Learning myself under guidance of teachers & $84 \%$ & $16 \%$ \\
\hline
\end{tabular}

Problems: Which areas of English are the biggest problems for you?

\begin{tabular}{|l|l|l|}
\hline Areas & Yes & No \\
\hline Speaking & $44 \%$ & $56 \%$ \\
\hline Listening & $20 \%$ & $80 \%$ \\
\hline Reading & $8 \%$ & $92 \%$ \\
\hline Writing & $28 \%$ & $62 \%$ \\
\hline Vocabulary & $60 \%$ & $40 \%$ \\
\hline Grammar & $64 \%$ & $36 \%$ \\
\hline
\end{tabular}




\section{Appendix: B}

\section{Appendix B: Survey Questionnaire-2 with results (25 students participated)}

Name:

Current Profession:

Age:

Date:

\section{Please read the following instructions before you fill up the questionnaire:}

[The questionnaire given below has been designed to get a general idea about you as per requirement of a small survey. This survey is conducted for a research paper titled "Need Analysis: An Invaluable Step for Successful Autonomous Learning". Therefore, it will be highly appreciated if you provide as much information as you can. Your honesty and patience will be highly honoured.]

\begin{tabular}{|l|l|l|l|}
\hline No & Questions & Yes & No \\
\hline 1 & I learn best when I chose what work I would like to do & $96 \%$ & $4 \%$ \\
\hline 2 & $\begin{array}{l}\text { I learn best when the teacher lets me discover answers by myself rather than just } \\
\text { hearing them }\end{array}$ & $80 \%$ & $20 \%$ \\
\hline 3 & I learn best when there is a friendly atmosphere in the classroom & $92 \%$ & $8 \%$ \\
\hline 4 & I like to work with other students in pairs and small groups & $92 \%$ & $8 \%$ \\
\hline 5 & I learn best when the teacher moves around the class and helps individual student & $96 \%$ & $4 \&$ \\
\hline 6 & I learn best when the teacher is strict and controls the lesson & $40 \%$ & $60 \%$ \\
\hline 7 & I like debates, short talks, presentations to express my own ideas and opinions & $96 \%$ & $4 \%$ \\
\hline 8 & I prefer to complete my assignments independently & $88 \%$ & $12 \%$ \\
\hline 9 & I prefer to correct my own work; not by the teacher & $52 \%$ & $48 \%$ \\
\hline 10 & I like to practise English outside the classroom also & $96 \%$ & $4 \%$ \\
\hline
\end{tabular}




\section{Appendix: C}

\section{Appendix C: Survey Questionnaire-3}

Name:

Current Profession:

Age:

Date:

\section{Please read the following instructions before you fill up the questionnaire:}

[The questionnaire given below has been designed to get a general idea about you as per requirement of a small survey. This survey is conducted for a research paper titled "Need Analysis: An Invaluable Step for Successful Autonomous Learning”. Therefore, it will be highly appreciated if you provide as much information as you can. Your honesty and patience will be highly honoured.]

1) How much interesting was your learning English at UIU?

2) Were you worried after getting admitted to UIU where the medium of instruction is English?

3) What type of environment did you like the most in case of learning English?

4) Did you learn English in this same way throughout your school/college life?

5) Do you think if you have got such an environment (as in UIU) earlier in your school, it could have been better?

6) What were the most useful factors that have contributed to your acquisition?

7) Did you really like learning English by taking responsibilities on your own?

8) How did you use to notice your mistakes, and how were you motivated to correct your mistakes?

9) Do you think you have overcome all your lacking? What are the skills you are good at now?

10) How fruitful was your learning in your ESL classroom? What do you think from your experience? 


\section{Appendix: D}

\section{Appendix D: Survey Questionnaire-4 with results (5 ESL teachers participated)}

\section{Name:}

\section{Current Profession:}

\section{Designation:}

Date:

Please read the following instructions before you fill up the questionnaire:

[The questionnaire given below has been designed to get a general idea about you as per requirement of a small survey. This survey is conducted for a research paper titled "Need Analysis: An Invaluable Step for Successful Autonomous Learning". Therefore, it will be highly appreciated if you provide as much information as you can. Your honesty and patience will be highly honoured.]

\begin{tabular}{|l|l|l|l|l|l|}
\hline No & Statement & All of them & $\begin{array}{l}\text { Most of } \\
\text { them }\end{array}$ & $\begin{array}{l}\text { Very few } \\
\text { of them }\end{array}$ & $\begin{array}{l}\text { None } \\
\text { of } \\
\text { them }\end{array}$ \\
\hline 1. & $\begin{array}{l}\text { Ss learn best when the teacher is strict and controls the } \\
\text { lesson }\end{array}$ & $20 \%$ & $80 \%$ & \\
\hline 2. & $\begin{array}{l}\text { Ss prefer discovering their own answers rather than just } \\
\text { hearing them }\end{array}$ & & $40 \%$ & $60 \%$ & \\
\hline 3. & $\begin{array}{l}\text { Ss learn best when there is a friendly atmosphere in the } \\
\text { classroom }\end{array}$ & $40 \%$ & $60 \%$ & & \\
\hline 4. & Ss like pair/ group work & $60 \%$ & $40 \%$ & $60 \%$ & $20 \%$ \\
\hline 5. & $\begin{array}{l}\text { Ss learn best when the teacher moves around the class } \\
\text { and helps individual student }\end{array}$ & $20 \%$ & & $100 \%$ \\
\hline 6. & Ss prefer to complete their assignments independently & & & \\
\hline 7. & Ss do not like to express themselves in front of the class & & $60 \%$ & $40 \%$ \\
\hline 8. & $\begin{array}{l}\text { Ss are motivated to take their own learning } \\
\text { responsibilities }\end{array}$ & & $80 \%$ & $20 \%$ \\
\hline 9. & $\begin{array}{l}\text { Ss are encouraged if their achievements are } \\
\text { acknowledged }\end{array}$ & $60 \%$ & $40 \%$ & & $40 \%$ \\
\hline 10. & Ss prefer to correct their own work; not by the teacher & & & $60 \%$ \\
\hline
\end{tabular}

\section{Copyrights}

Copyright for this article is retained by the author(s), with first publication rights granted to the journal.

This is an open-access article distributed under the terms and conditions of the Creative Commons Attribution license (http://creativecommons.org/licenses/by/4.0/). 